\title{
A Joint Dynamic Pricing, Advertising, and Production Model with Inventory-Level-Dependent Goodwill
}

\author{
Yongzhao Wang $\mathbb{D},{ }^{1}$ Liqun Wei $\mathbb{D}{ }^{2}$ and Jianxiong Zhang $\mathbb{D}^{2}$ \\ ${ }^{1}$ School of Mathematics and Statistics, Anyang Normal University, Anyang 455000, China \\ ${ }^{2}$ College of Management and Economics, Tianjin University, Tianjin 300072, China \\ Correspondence should be addressed to Liqun Wei; lqwei@tju.edu.cn
}

Received 10 February 2020; Revised 6 June 2020; Accepted 13 July 2020; Published 11 August 2020

Academic Editor: Silvia Romanelli

Copyright (C) 2020 Yongzhao Wang et al. This is an open access article distributed under the Creative Commons Attribution License, which permits unrestricted use, distribution, and reproduction in any medium, provided the original work is properly cited.

\begin{abstract}
Inventory level has a significant impact on the goodwill of products to customers, which seldom becomes the focus of previous studies. In this paper, joint dynamic pricing, advertising, and production decision-making problem is investigated, where the demand rate depends on sales price and goodwill. The inventory and backlog as well as advertisement are considered as goodwillbuilding factors. The optimal dynamic pricing, advertising, and production policies are derived by using Pontryagin's maximum principle. Numerical examples are provided to demonstrate the obtained results, and sensitivity analysis of main system parameters is carried out to obtain some managerial insights. We find that when the initial goodwill is relatively high, the firm's profit first decreases and then increases with respect to the impact intensity of inventory on goodwill; otherwise, the firm always benefits from a higher impact intensity of inventory on goodwill. Furthermore, the optimal production and advertising policies are complementary caused by the feature of inventory-dependent goodwill.
\end{abstract}

\section{Introduction}

The effect of inventory level on goodwill is extremely common in real situations. For example, in the supermarket, the item with large quantities displayed in the store generates a good impression that customers think the product is salable; on the contrary, the item which is often backlogged causes a terrible impression to customers. Glamorous display in large numbers with the help of modern light and electronic arrangements attracts the people and brings more customers for purchasing the items [1]. Observing/investigating this phenomenon, Levin et al. [2] first reported that there is a functional relationship between demand and stock level in a showroom/shop. The impression always plays an important role in accumulating the product's goodwill. The situation of inventory-level-dependent goodwill has a significant influence on the decision-making, and ignoring this situation will cause huge economic losses.

Considering that inventory level has a motivating effect on customers, previous researches pay more attention to the situation that inventory level has a direct effect on demand. In some retail contexts, stocking large quantities of inventory not only improve service levels but also stimulate demand. For instance, it is usually observed in the supermarket that display of the consumer goods in large quantities attracts more customers and generates higher demand [3]. This effect can be interpreted by the products that are almost the same but are individually slightly different in detail, thus enhancing inventory level can give the customer a wider selection and add the probability of making a sale. The first attempt to establish model for inventory-dependent demand was made by Gupta and Vrat [4]. We can see Urban [5] for a comprehensive review of the literature. The impact of inventory on demand has attracted many scholars, such as Khanna et al. [6] and Khara et al. [7]. In a dynamic framework, Alfares [8] considered the inventory policy for a product with a stock-level-dependent demand and a storagetime-dependent holding cost. An investigation on the dynamic of a supply chain system under stock-dependent demand was presented by Wei and Wang [9], where a 
switched linear model composed of three subsystems was developed considering the feature of piecewise linearity. Lu et al. [10] formulated an inventory model for deteriorating items with limited replenishment capacity to seek the optimal dynamic pricing strategy and replenishment cycle, where the demand rate depends on the sales price and the inventory level displayed in the store. Zhang et al. [11] studied an inventory control and pricing problem for noninstantaneous deteriorating items with inventorydependent demand.

The definitions of the mechanism of how the inventory affects demand put forward by researches are quite different. For example, Urban [5] discussed two distinct types of inventory control models, the demand rate was a function of the initial inventory level, and the demand rate was dependent on the instantaneous inventory level. However, inventory level as one kind of credible commitment of the firm, just like advertising, affects not only the current demand for the product but also the future demand. This phenomenon is seldom studied in the existing literature. Therefore, we consider the effect of inventory level on firm's reputation in a dynamic process that a higher inventory level leads to a higher rate of goodwill increase. This setting is significantly and essentially different from previous work. On the other hand, when the inventory is negative, a positive backlog will undoubtedly damage goodwill. This fact is characterized in most of the studies by backlog, where the backlog cost is interpreted as goodwill loss of firm, such as Bhaskaran et al. [12]; Iravani et al. [13]; Chandra et al. [14]; Ramkishore and Amit [15]; and Chandra et al. [16]. However, our paper is the first one to capture the negative impact of backlog on goodwill in a dynamic process; that is, a higher backlog leads to a higher goodwill decrease rate.

Considering the situation of inventory-level-dependent goodwill, firms then take marketing and operation strategies to maximize profit. Pricing, as one of the most important strategies of the modern firms, plays an increasingly important role in sales and marketing. Managers can control prices to influence demand in the short run because of the price-sensitive of customers. The investigation of Marn et al. [17], McKinsey's study, reported that a $1 \%$ improvement in pricing can bring about an $8 \%$ improvement in profits for a typical S\&P 1500 company. Another fundamental component of the daily operations of firms is advertising. Advertisement has been widely adopted by companies to attract new customers and simulate demand because it signals the existence of the product [18]. Firms would like to increase the advertising expenditure to distribute the advertising messages through various mass media especially electronic media. It is estimated that advertising spending worldwide will surpass 560 billion US dollars in 2019, representing a growth of roughly 4 percent compared with the previous year [19]. Thus price and advertisement are two key marketing tools, and firms are required to make appropriate pricing and advertising decisions simultaneously.

There are a long history and extensive literature on models of combining advertising and pricing since the pioneering work of Dorfman and Steiner [20]. We can see the surveys of Mahajan et al. [21]; Bagwell [22]; Chen and
Xie [23]; and Taleizadeh et al. [24] for details and annotated bibliographies. These models typically consider the introduction of new goods, the third-party product, and the market share of a product with the objective of maximizing total profits. Furthermore, Baye and Morgan [25] modeled the environment where e-retailers sell similar products and endogenously engage in both advertising and pricing. When considering potential competitors, SeyedEsfahania et al. [26] coordinated pricing and vertical coop advertising in manufacturer-retailer supply chains using game theory. Yue et al. [27] studied pricing and advertisement decisions in a manufacturer-retailer supply chain when price discounts are offered by both the manufacturer and retailer. Karray and Martin-Herran [28] investigated whether manufacturers can use the timing of their pricing and advertising decisions to benefit from or to deter store brand introductions.

In the aforementioned literature for optimal pricing and advertising policies, the studies have been confined to onetime pricing and static advertising that the demand has a direct relationship with the frequency of advertisement. As the development of technology innovation such as the increased availability of demand data and the ease of changing prices, it is possible to make dynamic pricing. Dynamic pricing refers to the strategy that firms can adjust the sales price flexibly according to the demand and supply capacity to maximize the profit. Meanwhile, considering the longtime effects of advertising on reputation, firms can contribute to the accumulation of reputation by advertising and achieve its market share and profitability target in the long run. Using the dynamic control strategies, dynamic pricing and dynamic advertising, is particularly helpful to regulate the sales problem, which is widely studied. Particularly, under the case of isoelastic demand, the impact of discounting and specific adoption effects has been studied intensively in an infinite horizon framework, for example, Sethi et al. [29] and Helmes et al. [30]. For the extension of competition between supply chain members, He et al. [31] considered a dynamic stochastic supply chain and provided in feedback form the optimal advertising and pricing policies for the manufacturer and the retailer. Chutani and Sethi [32] modeled a dynamic advertising and pricing model by considering the duopoly with two competing retailers. Liu et al. [33] considered a firm composed of an operations department and a marketing department, in which the operations department is responsible for the quality improvement of the product, while the marketing department controls the retail price and advertising effort. Feng et al. [34] proposed a dynamic optimization model to maximize total profit by setting a joint pricing and advertising policy under the constraint of a limited advertising capacity. Wu et al. [35] investigated the pricing and advertising decisions by considering the effect of number of the platform users on demand in the dynamic setting.

In Table 1, a comparative analysis is presented which appropriately positions the work of this paper. To the best of the authors' knowledge, this may be the first research study that integrates joint pricing, advertising, and production policies problem for the durable product with inventory and backlog. 
TABLE 1: Contemporary literature review.

\begin{tabular}{|c|c|c|c|c|c|c|}
\hline Literature & Advertising & Pricing & Production & Inventory & Backlog & Environment \\
\hline Gupta and Vrat [4] & & & $\sqrt{ }$ & $\sqrt{ }$ & & Static \\
\hline Urban [5] & & & $\sqrt{ }$ & $\sqrt{ }$ & $\sqrt{ }$ & Static \\
\hline Lu et al. [10] & & $\sqrt{ }$ & $\sqrt{ }$ & $\sqrt{ }$ & & Static \\
\hline Zhang et al. [11] & & $\sqrt{ }$ & & $\sqrt{ }$ & & Dynamic \\
\hline Baye and Morgan [25] & $\sqrt{ }$ & $\sqrt{ }$ & & & & Static \\
\hline SeyedEsfahania et al. [26] & $\sqrt{ }$ & $\sqrt{ }$ & & & & Static \\
\hline Yue et al. [27] & $\sqrt{ }$ & $\sqrt{ }$ & & & & Static \\
\hline Karray and Martin-Herran [28] & $\sqrt{ }$ & $\sqrt{ }$ & & & & Static \\
\hline He et al. [31] & & $\sqrt{ }$ & & $\sqrt{ }$ & & Dynamic \\
\hline Chutani and Sethi [32] & $\sqrt{ }$ & $\sqrt{ }$ & & & & Dynamic \\
\hline Liu et al. [33] & $\sqrt{ }$ & $\sqrt{ }$ & & $\sqrt{ }$ & & Dynamic \\
\hline Feng et al. [34] & $\sqrt{ }$ & $\sqrt{ }$ & & $\sqrt{ }$ & & Dynamic \\
\hline This paper & $\sqrt{ }$ & $\sqrt{ }$ & $\sqrt{ }$ & $\sqrt{ }$ & $\sqrt{ }$ & Dynamic \\
\hline
\end{tabular}

Focus of the problem studied in our setting is different from the available investigations in the following aspects. Firstly, inventory and backlog are considered as goodwillbuilding factors like advertisement. Secondly, we consider joint pricing, advertising, and production policies problem for the durable product. Finally, continuous time and dynamic environment are presented in this paper. Taking the aforementioned points into account, we establish a production-inventory model of a monopolistic firm which controls production and sales together and seek the optimal pricing, advertising, and production policies to maximize the total profit under the planning horizon, where the demand rate depends on the sales price and goodwill level. The goodwill level is accumulated by the advertising in the most available literature, while we consider that the inventory and backlog are also goodwill-building factors, which is the focus and contribution of this study from the modeling viewpoint. The questions we are concerned about are as follows: What are the optimal production, pricing, and advertising strategies of the firm when the inventory and backlog affect goodwill? What are the interactions between the strategies? How does the impact intensity of inventory on goodwill affect the firm's profit? The model proposed is a dynamic optimization problem and can be solved by using Pontryagin's maximum principle. Numerical examples and sensitivity analysis of main system parameters are provided to demonstrate the obtained results. Several interesting results emerge. It is shown that when the initial goodwill is relatively high, the total profit may decrease firstly and then increase with respect to the impact intensity of inventory on goodwill. When the initial goodwill is relatively low, the firm always benefits from a higher impact intensity of inventory on goodwill. What is more, as the inventory plays a role in promoting goodwill, the optimal production and advertising strategies become strategically complementary.

The paper is organized as follows. In the next section, we formulate the mathematical model of the optimization problem. In Section 3, joint optimal policies are obtained by solving the corresponding problem. Section 4 investigates the model with numerical studies, and Section 5 concludes the paper.

\section{Model}

In this study, we consider a monopolistic firm that produces a kind of durable item and sells it directly to consumers in a finite planning horizon $[0, T]$. We set the terminal instant $T$ fixed, exogenous, and relatively short, which is a common setting in operations management studies [36,37]. The firm aims to optimize the total profit through marketing and operations tools. Pricing is elementary and an extremely efficient tool used by managers to earn profit, and advertising is also a prevalent marketing tool adopted to improve sales. Additionally, production is a basic operations tool whose function is to minimize the cost under the condition that demand is satisfied.

We consider that the inventory and backlog are goodwill-building factors. Specifically, the positive inventory level has a positive influence on goodwill, where a higher inventory level induces higher goodwill. Conversely, the negative inventory level, that is, backlog, has a negative influence on goodwill, where a higher backlog level decreases goodwill. Both inventory and backlog levels are denoted by $I(t)$ at time $t$, where $I(t) \geq 0$ represents inventory level and $I(t)<0$ represents a positive backlog level. Introducing this effect of inventory on goodwill, we modify the well-known Nerlove and Arrow model [38] as

$$
\dot{G}(t)=a(t)-\delta G(t)+\eta I(t), \quad G(0)=G_{0},
$$

where $G(t)$ represents the goodwill at time $t$ with the initial value denoted as $G(0)=G_{0}>0, a(t)$ denotes the advertising rate at time $t, \eta$ measures the marginal effect of inventory on goodwill, and $\delta$ is the decay rate of goodwill due to customers' forgetting effect.

The goodwill, as we all know, has a close relationship with consumer demand, so the demand rate is supposed to 
depend not only on price but also on the stock of goodwill. Denote the price charged by the firm at time $t$ as $p(t)$. The demand rate $D(G(t), p(t))$ is assumed to increase with the goodwill $G(t)$ but decrease with the price $p(t)$ according to the following function:

$$
D(G(t), p(t))=\alpha-\beta p(t)+\gamma G(t),
$$

where $\alpha$ is the basic market potential, $\beta$ reflects the elasticity of the demand with respect to price, and $\gamma$ is a positive parameter capturing the effect of goodwill on current sales. This linear demand function is commonly applied in the economics literature such as De Giovanni [39]; Erickson [40], and Li et al. [41].

The inventory system for the firm is considered along a horizon $[0, T]$. In order to maximize the profit, the inventory level equals zero at $T$. The inventory decreases due to demand but can be replenished by the production rate $u(t)$ which is under direct control of the firm. Based on the above description, inventory level evolves according to the difference between production and demand; that is,

$$
\dot{I}(t)=-D(G(t), p(t))+u(t), \quad I(0)=I_{0}, I(T)=0,
$$

where $I_{0}$ denotes initial inventory level. Inventory level can be negative, which indicates a positive backlog. This is consistent with the study shown by Erickson [42] where backlog is allowed; that is, production and delivery to customer can be delayed at a cost to the firm. The basic economic reason for backlog is that backlogging allows the deferring of production cost. But on the other hand, the more backlog results in the lower goodwill.

The cost of advertising effort, $C_{1}(a(t))$, is described by the following quadratic function:

$$
C_{1}(a(t))=\frac{1}{2} k_{1} a^{2}(t)
$$

where $k_{1}>0$ is a scaling parameter. We can comprehend the convex advertising cost as follows: in order to increase advertising over certain levels, a firm has to resort to additional advertising channels which are less efficient or more expensive. The production cost is also assumed to be quadratic in the production rate; that is,

$$
C_{2}(u(t))=\frac{1}{2} k_{2} u^{2}(t)
$$

where $k_{2}$ is a positive constant. In this way, the production cost is convex increasing with production rate. Note that this quadratic cost function of advertising and production is a regular assumption in existing literature such as Pekelman [43]; Prasad and Sethi [44]; Zaccour [45]; and Wang and Sun [46]. Finally, the cost of the current inventory/backlog is expressed as

$$
C_{3}(I(t))=h I^{2}(t)
$$

where $h$ is the positive holding cost or backlog cost coefficient. This is consistent with the general relationship suggested in Feichtinger and Hartl [47] that both the values of cost function and the first derivative of the cost function should be zero at an inventory/backlog level of zero, and the second derivative of the cost function should be positive.

The firm's objective is to maximize the sum of cash flow along the planning horizon $[0, T]$, where instantaneous cash flow is sales revenue minus the costs of advertising, production, and inventory/backlog:

$$
J=\int_{0}^{T}\left[p(t) D(G, p)-C_{1}(a(t))-C_{2}(u(t))-C_{3}(I(t))\right] \mathrm{d} t .
$$

So, the firm's optimization problem can be formulated as

$$
\begin{array}{ll}
\max _{p(\cdot), a(\cdot), u(\cdot)} \quad J=\int_{0}^{T}\left(p(t)(\alpha-\beta p(t)+\gamma G(t))-\frac{1}{2} k_{1} a^{2}(t)-\frac{1}{2} k_{2} u^{2}(t)-h I^{2}(t)\right) \mathrm{d} t \\
& \dot{G}(t)=a(t)-\delta G(t)+\eta I(t), G(0)=G_{0} \\
\text { s.t. } \quad & \dot{I}(t)=-\alpha+\beta p(t)-\gamma G(t)+u(t), I(0)=I_{0}, I(T)=0 \\
& p(t) \geq 0, a(t) \geq 0, u(t) \geq 0 .
\end{array}
$$


The optimization problem (8) is an optimal control problem with two state variables, $G(t), I(t)$, and three controls, $p(t), a(t), u(t)$.

\section{Solution Method}

In this section, the optimization problem (8) can be solved by applying Pontryagin's maximum principle proposed in
Sethi and Thompson [48]. Associating adjoint variables $\lambda_{1}(t)$ and $\lambda_{2}(t)$ with the objective function, the Hamiltonian function can be written as

$$
\begin{aligned}
H\left(G, I, p, a, u, \lambda_{1}, \lambda_{2}, t\right)= & p(t)(\alpha-\beta p(t)+\gamma G(t))-\frac{k_{1}}{2} a^{2}(t)-\frac{k_{2}}{2} u^{2}(t)-h I^{2}(t) \\
& +\lambda_{1}(t)(a(t)-\delta G(t)+\eta I(t))+\lambda_{2}(t)(-\alpha+\beta p(t)-\gamma G(t)+u(t)) .
\end{aligned}
$$

For the adjoint variables $\lambda_{1}$ and $\lambda_{2}$, we obtain the adjoint equations $\dot{\lambda}_{1}(t)=-\partial H / \partial G$ and $\dot{\lambda}_{2}(t)=-\partial H / \partial I$; namely,

$$
\begin{aligned}
& \dot{\lambda}_{1}(t)=-\gamma p(t)+\delta \lambda_{1}(t)+\gamma \lambda_{2}(t), \\
& \dot{\lambda}_{2}(t)=2 h I(t)-\eta \lambda_{1}(t),
\end{aligned}
$$

because the terminal state of goodwill $G(T)$ is a free-end point, we obtain the transversality condition

$$
\lambda_{1}(T)=0 \text {. }
$$

The optimal control policies $\left(p^{*}(t), a^{*}(t), u^{*}(t)\right)$ and state trajectories $\left(G^{*}(t), I^{*}(t)\right)$ have to maximize the Hamiltonian function at all points; that is,

$$
\begin{aligned}
& H\left(G^{*}(t), I^{*}(t), p^{*}(t), a^{*}(t), u^{*}(t), \lambda_{1}(t) \lambda_{2}(t), t\right) \\
& \quad \geq H\left(G^{*}(t), I^{*}(t), p(t), a(t), u(t), \lambda_{1}(t) \lambda_{2}(t), t\right), \quad \forall t \in[0, T] .
\end{aligned}
$$

Because $H$ is a strictly concave function in $p, a$, and $u$, the optimal policy $\left(p^{*}, a^{*}, u^{*}\right)$ has to satisfy the first-order necessary conditions $\partial H / \partial p=0, \partial H / \partial a=0$, and $\partial H / \partial u=0$. Thus, we have

$$
p^{*}(t)= \begin{cases}0, & \gamma G(t)+\beta \lambda_{2}(t)<-\alpha, \\ \frac{\alpha+\gamma G(t)+\beta \lambda_{2}(t)}{2 \beta}, & -\alpha \leq \gamma G(t)+\beta \lambda_{2}(t) \leq \alpha, \\ \frac{\alpha+\gamma G(t)}{2 \beta}, & \gamma G(t)+\beta \lambda_{2}(t)>\alpha,\end{cases}
$$

$$
a^{*}(t)= \begin{cases}0, & \lambda_{1}(t)<0 \\ \frac{\lambda_{1}(t)}{k_{1}}, & \lambda_{1}(t) \geq 0\end{cases}
$$

$$
u^{*}(t)= \begin{cases}0, & \lambda_{2}(t)<0 \\ \frac{\lambda_{2}(t)}{k_{2}}, & \lambda_{2}(t) \geq 0\end{cases}
$$

Note that the boundary solutions yield no profit. Here, we only focus on the interior solutions, $p^{*}(t)=(\alpha+\gamma G(t)+$ $\left.\beta \lambda_{2}(t)\right) / 2 \beta, a^{*}(t)=\lambda_{1}(t) / k_{1}, u^{*}(t)=\lambda_{1}(t) / k_{2}$, and ignore the constraints $p(t) \geq 0, a(t) \geq 0, u(t) \geq 0, D(t) \geq 0$. What is more, in Section 4, it is verified that the constraints $p(t) \geq 0, a(t) \geq 0, u(t) \geq 0, D(t) \geq 0$ are satisfied for all $t \in[0, T]$.

Substituting the optimal control strategies into the dynamic evolution equations of states and adjoint variables, we can get the following four-equation system:

$$
\left\{\begin{array}{l}
\dot{G}(t)=-\delta G+\eta I+\frac{1}{k_{1}} \lambda_{1}, \\
\dot{I}(t)=-\frac{\gamma}{2} G+\left(\frac{\beta}{2}+\frac{1}{k_{2}}\right) \lambda_{2}-\frac{\alpha}{2}, \\
\dot{\lambda}_{1}(t)=-\frac{\gamma^{2}}{2 \beta} G+\delta \lambda_{1}+\frac{\gamma}{2} \lambda_{2}-\frac{\alpha \gamma}{2 \beta}, \\
\dot{\lambda}_{2}(t)=-2 h I-\eta \lambda_{1} .
\end{array}\right.
$$

By solving the differential equation (16), the optimal policies and states are presented in the following proposition.

Proposition 1. The optimal pricing, advertising, and production strategies can be, respectively, given by 


$$
\begin{aligned}
& p^{*}(t)=\frac{\gamma\left(\beta \delta \eta k_{1} k_{2}-\beta \eta k_{1} k_{2} v_{1}+2 \delta \eta k_{1}-2 \eta k_{1} v_{1}-k_{2} \gamma v_{1}\right)+n_{1}}{2 n_{1}} c_{1} e^{v_{1} t} \\
& -\frac{\gamma\left(\beta \delta \eta k_{1} k_{2}+\beta \eta k_{1} k_{2} v_{1}+2 \delta \eta k_{1}+2 \eta k_{1} v_{1}+k_{2} \gamma v_{1}\right)-n_{2}}{2 n_{2}} c_{2} e^{-v_{2} t} \\
& +\frac{\gamma\left(\beta \delta \eta k_{1} k_{2}+\beta \eta k_{1} k_{2} v_{2}+2 \delta \eta k_{1}-2 \eta k_{1} v_{2}-k_{2} \gamma v_{2}\right)+n_{3}}{2 n_{3}} c_{3} e^{v_{2} t} \\
& -\frac{\gamma\left(\beta \delta \eta k_{1} k_{2}+\beta \eta k_{1} k_{2} v_{2}+2 \delta \eta k_{1}+2 \eta k_{1} v_{2}+k_{2} \gamma v_{2}\right)-n_{4}}{2 n_{4}} c_{4} e^{-v_{2} t} \\
& +\frac{\alpha\left(2 \beta^{2} \delta^{2} h k_{1} k_{2}+\eta^{2} k_{1} \gamma^{2}+2 h \gamma^{2}+w\right)}{2 \beta w} \\
& a^{*}(t)=\frac{k_{1} \gamma\left(-\beta \delta k_{2} v_{1}-\beta k_{2} v_{1}^{2}+\eta \gamma\right) c_{1}}{n_{1} k_{1}} e^{v_{1} t}+\frac{k_{1} \gamma\left(-\beta \delta k_{2} v_{1}+\beta k_{2} v_{1}^{2}-\eta \gamma\right) c_{2}}{n_{2} k_{1}} e^{-v_{1} t} \\
& +\frac{k_{1} \gamma\left(-\beta \delta k_{2} v_{2}-\beta k_{2} v_{2}^{2}+\eta \gamma\right) c_{3}}{n_{3} k_{1}} e^{v_{2} t}+\frac{k_{1} \gamma\left(-\beta \delta k_{2} v_{2}+\beta k_{2} v_{2}^{2}-\eta \gamma\right) c_{2}}{n_{4} k_{1}} e^{-v_{2} t} \\
& +\frac{\left(\beta k_{2}+2\right) h \delta \alpha \gamma-\alpha \gamma \beta \delta h k_{2}}{2 w} \\
& u^{*}(t)=\frac{c_{1}}{k_{2}} e^{v_{1} t}+\frac{c_{2}}{k_{2}} e^{-v_{1} t}+\frac{c_{3}}{k_{2}} e^{v_{2} t}+\frac{c_{4}}{k_{2}} e^{-v^{2} t} \\
& +\frac{\left(\eta^{2} k_{1}+2 h\right) \gamma^{2} \alpha+\alpha\left(4 \beta \delta^{2} h k_{1}-\eta^{2} \gamma^{2} k_{1}-2 h \gamma^{2}\right)}{2 w}
\end{aligned}
$$

and the optimal state trajectory of goodwill and inventory/ backlog, respectively, is

$$
\begin{aligned}
& G^{*}(t)=\frac{\beta\left(\beta \delta \eta k_{1} k_{2}-\beta \eta k_{1} k_{2} v_{1}+2 \delta \eta k_{1}-2 \eta k_{1} v_{1}-k_{2} \gamma v_{1}\right) c_{1}}{n_{1}} e^{v_{1} t} \\
& -\frac{\beta\left(\beta \delta \eta k_{1} k_{2}+\beta \eta k_{1} k_{2} v_{1}+2 \delta \eta k_{1}+2 \eta k_{1} v_{1}+k_{2} \gamma v_{1}\right) c_{2}}{n_{2}} e^{-v_{1} t} \\
& +\frac{\beta\left(\beta \delta \eta k_{1} k_{2}-\beta \eta k_{1} k_{2} v_{2}+2 \delta \eta k_{1}-2 \eta k_{1} v_{2}-k_{2} \gamma v_{2}\right) c_{3}}{n_{3}} e^{v_{2} t} \\
& -\frac{\beta\left(\beta \delta \eta k_{1} k_{2}+\beta \eta k_{1} k_{2} v_{2}+2 \delta \eta k_{1}+2 \eta k_{1} v_{2}+k_{2} \gamma v_{2}\right) c_{4}}{n_{4}} e^{-v_{2} t} \\
& +\frac{\left(\beta k_{2}+2\right)\left(\eta^{2} k_{1}+2 h\right) \alpha \gamma-\left(\eta^{2} k_{1}+2 h\right) \alpha \gamma \beta k_{2}}{2 w}, \\
& I^{*}(t)=\frac{\left(\beta^{2} \delta^{2} k_{1} k_{2}-\beta^{2} k_{1} k_{2} v_{1}^{2}+2 \beta \delta^{2} k_{1}-2 \beta k_{1} v_{1}^{2}-\gamma^{2}\right) c_{1}}{n_{1}} e^{v_{1} t} \\
& -\frac{\left(\beta^{2} \delta^{2} k_{1} k_{2}-\beta^{2} k_{1} k_{2} v_{1}^{2}+2 \beta \delta^{2} k_{1}-2 \beta k_{1} v_{1}^{2}-\gamma^{2}\right) c_{2}}{n_{2}} e^{-v_{1} t} \\
& +\frac{\left(\beta^{2} \delta^{2} k_{1} k_{2}-\beta^{2} k_{1} k_{2} v_{1}^{2}+2 \beta \delta^{2} k_{1}-2 \beta k_{1} v_{2}^{2}-\gamma^{2}\right) c^{3}}{n_{3}} e^{v_{2} t} \\
& -\frac{\left(\beta^{2} \delta^{2} k_{1} k_{2}-\beta^{2} k_{1} k_{2} v_{2}^{2}+2 \beta \delta^{2} k_{1}-2 \beta k_{1} v_{2}^{2}-\gamma^{2}\right) c_{4}}{n_{4}} e^{-v_{2} t} \\
& +\frac{\left(\beta k_{2}+2\right) \eta \delta \alpha \gamma k_{1}-\alpha \eta \delta \gamma \beta k_{1} k_{2}}{2 w} \text {. }
\end{aligned}
$$


Value of the notations $v_{1}, v_{2}, w, n_{1}, n_{2}, n_{3}, n_{4}, c_{1}, c_{2}, c_{3}$, and $c_{4}$ and proof of the proposition can be found in Appendix. This proposition shows the time path of the optimal dynamic pricing, advertising, and production policies and the corresponding time path of the optimal goodwill and inventory/backlog states. However, it is hard to analytically obtain more managerial insights directly from the optimal policies since the analytical expressions of optimal policies and states are complicated. In this way, we use numerical examples to obtain more visual results.

\section{Numerical Examples}

In this section, we present some numerical examples to illustrate the theoretical results. The focus of this paper is to study the effect of inventory/backlog on goodwill and the influence on other strategies. So we only change parameter $\eta$ and keep the remaining parameters unchanged. The following parameter values are set as a benchmark:

$$
\begin{aligned}
& \text { Demand parameters: } \alpha=10, \beta=1, \gamma=0.3 \\
& \text { Goodwill parameters: } \delta=0.4, \eta=0.2, G_{0}=15, k_{1}=1 \\
& \text { Inventory parameters: } h=0.4, I_{0}=0, I(T)=0 \\
& \text { Production parameter: } k_{2}=3 \\
& \text { Planning horizon: } T=30
\end{aligned}
$$

These parameter values are chosen from the previous studies of dynamic production, pricing, and advertising strategies, which allow for a comprehensive illustration. With the given data, we can get the different time paths of $u^{*}(t), a^{*}(t), p^{*}(t)$ under different values of parameter $\eta$ in Figures $1-3$, and then we can obtain the corresponding optimal inventory/backlog level and goodwill level. The time path $I^{*}(t)$ is depicted in Figure 4.

Figure 4 depicts the inventory level curves under different values of $\eta$. From the different curves, we can see that, with a greater impact of inventory on goodwill, the inventory level has stronger volatility. It can be interpreted by the fact that when $\eta$ is relatively large, the inventory level has a greater impact on goodwill, and the firm will try to maintain a high inventory level, which aims to increase the goodwill and finally enhance the demand. Meanwhile, the negative inventory level, that is, backlog, must be the worst for the firm because it has a large negative impact on goodwill and leads to the decrease of goodwill. It is reasonable that firm would like to increase inventory level as much as possible in the early period of planning horizon (e.g., $t \in[0,10]$ ), which increases the goodwill and then in turn leads to high demand. Therefore, the inventory level presents high volatility. Specifically, the inventory increases sharply in the early period, then maintains a high level, and is emptied at the end of planning horizon. When $\eta$ is relatively small, the inventory has less impact on goodwill such that the firm is more concerned about production cost. Due to the increasing marginal production cost verified from the quadratic cost function of production, the firm tries to maintain a relatively smooth production rate to avoid the high production cost (shown in the production curve, i.e., Figure 1). It is optimal for the firm to hold a relatively low inventory

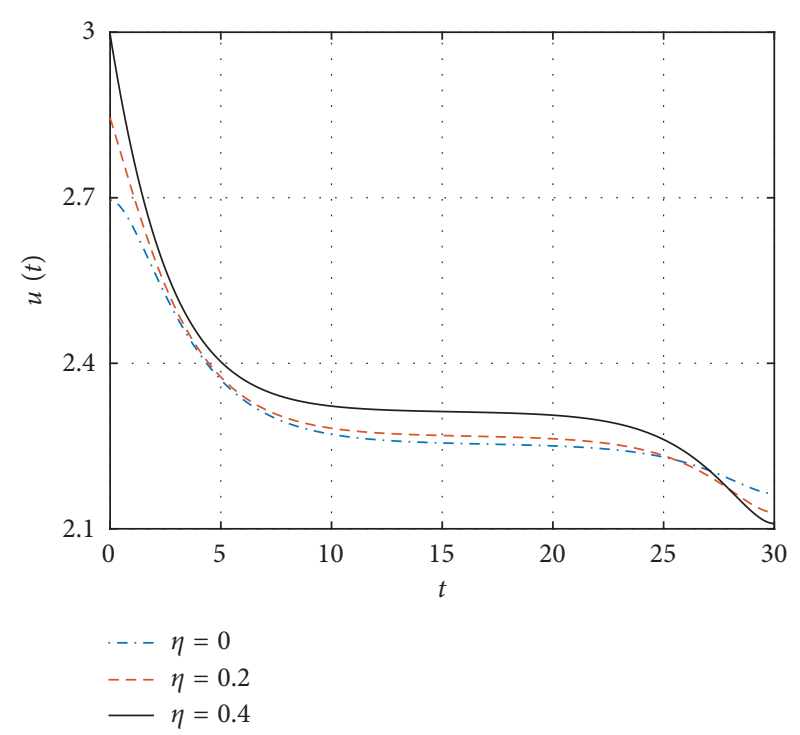

FIGURE 1: The optimal production strategy with different values of parameters $\eta$.



FIGURE 2: The optimal advertising strategy with different values of parameters $\eta$.

level even if backlog occurs, which can be seen from the inventory curve when $\eta$ is equal to 0 or 0.2 . Particularly, when inventory has no effect on goodwill (i.e., $\eta=0$ ), inventory level is always negative, which means that the firm always backlogs the order during the planning horizon. In the early period of planning horizon, the demand is pretty high due to the high initial goodwill level; however, it is not most profitable for firm to afford the high production cost to meet all the demand immediately. In this way, the backlog arises. As the demand decreases (shown in Figure 5), the firm covers the backlog gradually under a smooth production rate. Then in the middle period of planning horizon (e.g., $t \in[10,25]$ ), the inventory maintains relatively stable level. In the final period of planning horizon (e.g., 


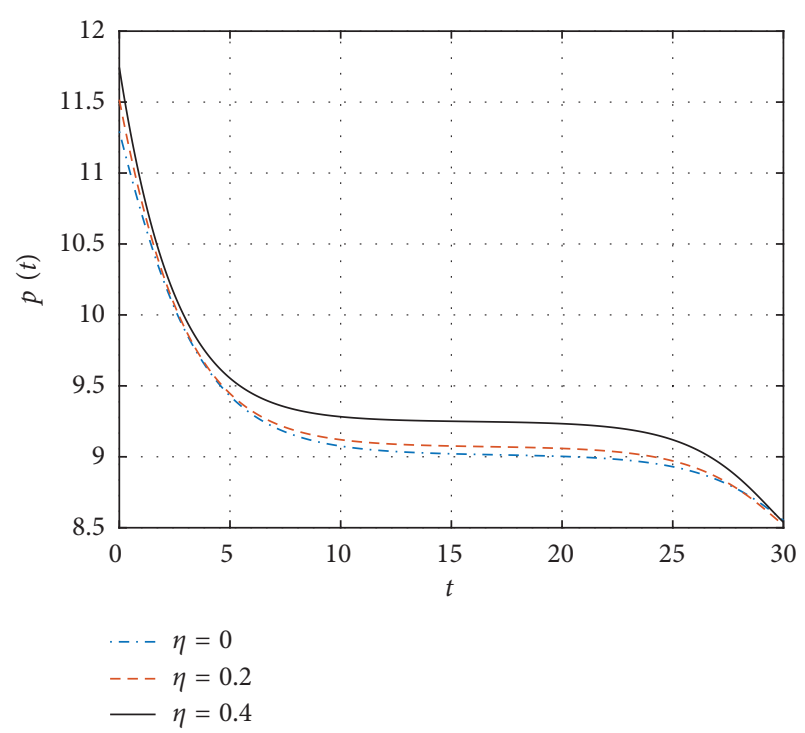

FIgURE 3: The optimal dynamic pricing strategy with different values of parameters $\eta$.



FIGURE 4: The optimal inventory with different values of parameters $\eta$.

$t \in[25,30])$, both the demand and production rate decrease; however, in order to follow a smooth production rate, production rate decreases earlier than demand. Thus, when $\eta=0$, a slight backlog arises near the end of the planning horizon, and finally the inventory level reaches zero.

Figure 1 shows three curves indicating the optimal production strategies with different values of parameter $\eta$. The comparison of the three curves shows that, except near the end of planning horizon, as $\eta$ becomes larger, the production rate is higher, and the total production quantity of the whole planning horizon is larger. Moreover, the larger $\eta$ is, the higher the increase of production rate is (compared with a smaller $\eta$ ). For example, the increment between $\eta=0.4$ and $\eta=0.2$ is significantly larger than that between $\eta=0.2$ and

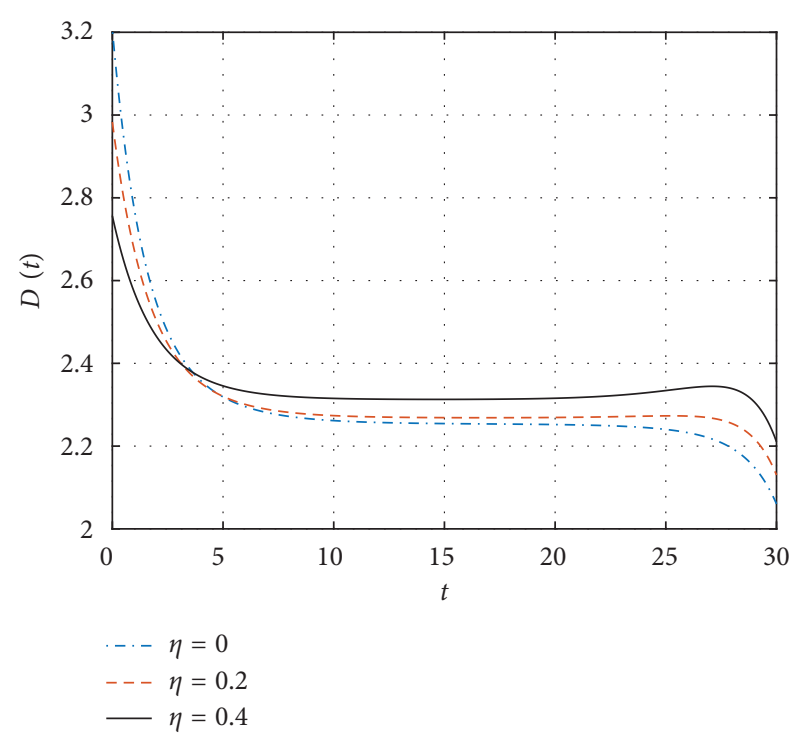

Figure 5: The optimal demand with different values of parameters $\eta$.

$\eta=0$. Specifically, when $\eta$ is relatively large, the firm chooses a high inventory strategy (shown in Figure 4), which brings high levels of goodwill and demand. Thus, in the early and middle periods of planning horizon, the production rate maintains a high level to increase inventory level and meet the high demand. In the final period of planning horizon, in order to consume all of the inventory at the end of the planning horizon $(t=T)$, the firm implements a relatively low production rate and meets the parts of demand with the aid of the products in inventory. What is more, we can also see that the curves of optimal production strategy when $\eta$ is relatively low have a similar variation trend as that of a higher $\eta$. Specifically, the production rate decreases in the early period of planning horizon, then maintains stable, and decreases again in the final period. It can be interpreted by the fact that, in the early period, the initial goodwill level is pretty high, which leads to high demand. The optimal production quantity would not satisfy all the demand initially because a high production rate will incur a pretty high cost. However, if the production rate is much lower than the demand rate, there may arise a pretty high backlog cost. Under this condition, the firm must balance the production cost and backlog cost. Therefore, in the early period, the production rate is relatively high compared with that in the middle period, and the production rate will gradually decrease following with the decrease of demand. In the middle period, the production rate is consistent with demand rate roughly. Finally, the production rate decreases due to the decrease of demand.

Figure 2 depicts the optimal advertising rate curves with different values of $\eta$. Interestingly, except the short initial period of planning horizon, a higher $\eta$ leads to a higher advertising rate. And the larger $\eta$ is, the higher the increase of advertising rate is (compared with a smaller $\eta$ ). For example, the increment of $\eta=0.4$ compared with $\eta=0.2$ is significantly larger than that of $\eta=0.2$ compared with $\eta=0$. Combined with the observation in Figure 1, it is shown that when the inventory plays a role in promoting goodwill, the 
production strategy and the advertising strategy are strategically complementary. It is due to the fact that, facing a relatively high $\eta$, the firm has incentives to maintain a high inventory level by increasing production. In order to consume these productions and inventories, a higher advertising rate is required to further stimulate demand, which eventually achieves a higher profit. In the short initial period of planning horizon, for a relatively small $\eta$, the inventory has a small impact on goodwill, and the firm mainly relies on advertising to maintain goodwill; thus, a higher advertising rate strategy is adopted. What is more, regardless of the value of $\eta$, except near the end of planning horizon, the advertising rate always maintains at a stable and high level to stimulate demand, whereas near the end of planning horizon, the advertising rate rapidly decreases to zero. This is because in the final period of planning horizon, there is less incentive for the firm to invest in advertising to maintain the goodwill and stimulate demand, and the advertising rate falls for the purpose of cost-saving.

Figure 3 shows the optimal pricing curves with respect to $\eta$. From Figures 2 and 4, we know that a higher $\eta$ leads to a higher inventory level and a higher advertising investment; thereby, the goodwill level is higher, which eventually leads to higher market size (i.e., $\alpha+\gamma G(t)$ ). Thus, the firm adopts a higher price to increase the marginal profit. Meanwhile, it is observed that the price is high initially due to high initial goodwill, and then the price maintains at a stable level. In the final period, because the goodwill further decreases, the firm lowers the price to stimulate the demand for emptying the inventory.

Figure 5 depicts the optimal demand curves with different values of $\eta$. Interestingly, when $\eta$ is higher, the demand is higher in the middle and final periods; however, the demand is lower in the early period. This is because, in the early period, when $\eta$ is higher, the firm also needs to allocate part of the production quantity to the inventory to increase goodwill, which eventually facilitates the sales of the whole planning horizon. Therefore, as $\eta$ increases, the firm has a stronger incentive to set a higher price in the early period (shown in Figure 3), which combined with the reduced advertising strategy (shown in Figure 2) makes the market demand decrease. This also contributes to a rapid increase of inventory level (shown in Figure 4) and thereby brings a greater positive impact on increase of goodwill. During the following operation period, for a larger $\eta$, the demand will be higher because of the high goodwill (resulted in high inventory level and high advertising rate). What is more, when $\eta=0.4$, there is a slight increase in demand under $t \in[24,28]$; this is caused by a decreasing pricing strategy with the aim for emptying the inventory.

Next, we study how the total profit varies with different values of parameter $\eta$ under different initial goodwill levels $G_{0}$. Figures 6(a) and 6(b) depict the total profit with respect to $\eta$ when $G_{0}=5$ and $G_{0}=15$, respectively. As shown in Figure 6(a), the total profit increases with $\eta$ for the entire planning horizon; it can be interpreted by the fact that, under a relatively small initial goodwill, there occurs no backlog for the firm, and the inventory level is almost

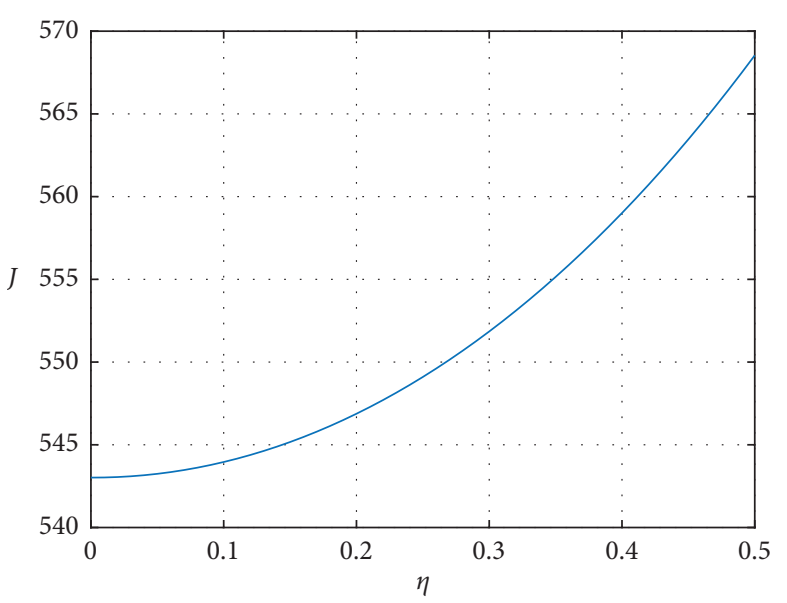

(a)

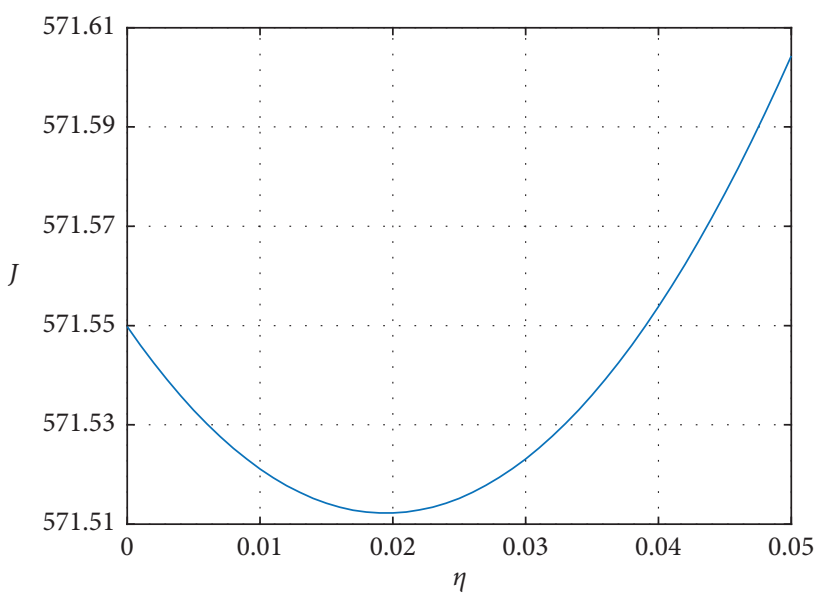

(b)

FIgure 6: The total profit with respect to $\eta$ under different initial goodwill $G_{0}$. (a) $G_{0}=15$. (b) $G_{0}=5$.

positive resulting in higher goodwill as $\eta$ increases, which in turn leads to a higher profit. However, one can observe the nonmonotonicity of the total profit with respect to $\eta$ in Figure 6(b). Based on the above analysis, we know that a relatively large initial goodwill greatly stimulates the demand; under the pressure of high production cost, it is difficult for a firm to meet the large market demand in time; thus, there is a short-term backlog. When $\eta$ is relatively low, that is, $\eta<0.02$ as shown in Figure 6(b), the negative inventory has a negative effect on goodwill; thus, the higher this effect is (a higher $\eta$ ), the lower the total profit is. Then as $\eta$ continues to increase (e.g., $\eta>0.02$ ), the firm would try to avoid the backlog, and thus the positive inventory effect increases the total profit for an increasing $\eta$.

\section{Conclusions}

In practice, it is common for a firm to manage production and retail together. This paper is concerned with a decision-making problem for a firm to jointly determine the production rate, sales price, and advertising rate in a dynamic setting. Inventory and backlog as well as 
advertisement are the goodwill accumulating factors. By solving the corresponding optimal control problem on the basis of Pontryagin's maximum principle, we obtain the joint optimal dynamic pricing, advertising, and production strategies. Numerical examples are provided to illustrate the effectiveness of the main theoretical results and the solution procedure. Then, sensitive analysis of the key system parameters is intensively investigated and some managerial insight is shown. The theoretical contribution and managerial implication can be summarized as follows. Firstly, this paper provides a framework to research the effect on the joint policy when inventory and backlog are goodwill-building factors. Secondly, the analytical solution of the optimal dynamic strategies serves as a powerful reference to support the managers in making the pricing, advertising, and production decision. Thirdly, several interesting results emerge from our research. Specifically, the total profit may decrease firstly and then increase with respect to the impact intensity of inventory on goodwill when the initial goodwill is relatively high. When the inventory plays a role in promoting goodwill, the optimal production and the advertising policies are strategically complementary.

In this paper, we focus on decision-making considering the influence of inventory on goodwill for a single product monopolist firm. For further studies, we can investigate the differential game problem between manufacturers and retailers under a competitive dynamic environment and explore the impact of the effect of goodwill on supply chain members' decision. In order to better study the actual business situation, both the goodwill and demand dynamics would naturally take uncertainty into account. Furthermore, it is interesting to investigate the costly price adjustment and defect management [49-51] based on the current model [52].

\section{Appendix}

We can rewrite system (16) by the following form:

$$
\left[\begin{array}{c}
\dot{G} \\
\dot{I} \\
\dot{\lambda_{1}} \\
\dot{\lambda_{2}}
\end{array}\right]=A\left[\begin{array}{c}
G \\
I \\
\lambda_{1} \\
\lambda_{2}
\end{array}\right]+B,
$$

where

$$
A=\left[\begin{array}{cccc}
-\delta & \eta & \frac{1}{k_{1}} & 0 \\
-\frac{\gamma}{2} & 0 & 0 & \left(\frac{\beta}{2}+\frac{1}{k_{2}}\right) \\
-\frac{\alpha \gamma}{2 \beta} & 0 & \delta & \frac{\gamma}{2} \\
0 & 2 h & -\eta & 0
\end{array}\right],
$$

$$
B=\left[\begin{array}{c}
0 \\
-\frac{\alpha}{2} \\
\alpha \gamma \\
-\frac{\alpha \beta}{2 \beta} \\
0
\end{array}\right] .
$$

The four eigenvalues of $A$ are $r_{1}=v_{1}, r_{2}=-v_{1}, r_{3}=v_{2}$, and $r_{4}=-v_{2}$, where

$$
\begin{aligned}
v_{1}= & \frac{\sqrt{\beta k_{1} k_{2}(m+\sqrt{\Delta})}}{2 \beta k_{1} k_{2}}, \\
v_{2}= & \frac{\sqrt{\beta k_{1} k_{2}(m-\sqrt{\Delta})}}{2 \beta k_{1} k_{2}}, \\
m= & 2 \beta^{2} h k_{1} k_{2}+2 \beta \delta^{2} k_{1} k_{2}-2 \beta \eta \gamma k_{1} k_{2}+4 \beta h k_{1}-\gamma^{2} k_{2}, \\
\Delta= & 4 \beta^{4} h^{2} k_{1}^{2} k_{2}^{2}-8 \beta^{3} \delta^{2} h k_{1}^{2} k_{2}^{2}-8 \beta^{3} \eta h k_{1}^{2} k_{2}^{2} \gamma+4 \beta^{2} \delta^{4} k_{1}^{2} k_{2}^{2}-8 \beta^{2} \delta^{2} \eta k_{1}^{2} k_{2}^{2} \gamma \\
& +4 \beta^{2} \eta^{2} k_{1}^{2} k_{2}^{2} \gamma^{2}+16 \beta^{3} h^{2} k_{1}^{2} k_{2}-16 \beta^{2} \delta^{2} h k_{1}^{2} k_{2}-16 \beta^{2} \eta h k_{1}^{2} k_{2} \gamma-4 \beta^{2} h k_{1} k_{2}^{2} \gamma^{2} \\
& -4 \beta \delta^{2} k_{1} k_{2}^{2} \gamma^{2}+8 \beta \eta^{2} k_{1}^{2} k_{2} \gamma^{2}+4 \beta \eta k_{1} k_{2}^{2} \gamma^{3}+16 \beta^{2} h^{2} k_{1}^{2}+8 \beta h k_{1} k_{2} \gamma^{2}+k_{2}^{2} \gamma^{4} .
\end{aligned}
$$


The eigenvector of A can be specified as

where

$$
H=\left[\begin{array}{llll}
x_{1} & x_{2} & x_{3} & x_{4}
\end{array}\right],
$$

$$
x_{1}=\left[\begin{array}{c}
\frac{\beta\left(\beta \delta \eta k_{1} k_{2}-\beta \eta k_{1} k_{2} v_{1}+2 \delta \eta k_{1}-2 \eta k_{1} v_{1}-k_{2} \gamma v_{1}\right)}{n_{1}} \\
\frac{\beta^{2} \delta^{2} k_{1} k_{2}-\operatorname{beta}^{2} k_{1} k_{2} v_{1}^{2}+2 \beta \delta^{2} k_{1}-2 \beta k_{1} v_{1}^{2}-\gamma^{2}}{n_{1}} \\
\frac{k_{1} \gamma\left(-\beta \delta k_{2} v_{1}-\beta k_{2} v_{1}^{2}+\eta \gamma\right)}{n_{1}} \\
1
\end{array}\right],
$$$$
x_{2}=\left[\begin{array}{c}
-\frac{\beta\left(\beta \delta \eta k_{1} k_{2}+\beta \eta k_{1} k_{2} v_{1}+2 \delta \eta k_{1}+2 \eta k_{1} v_{1}+k_{2} \gamma v_{1}\right)}{n_{2}} \\
-\frac{\beta^{2} \delta^{2} k_{1} k_{2}-\text { beta }^{2} k_{1} k_{2} v_{1}^{2}+2 \beta \delta^{2} k_{1}-2 \beta k_{1} v_{1}^{2}-\gamma^{2}}{n^{2}} \\
\frac{k_{1} \gamma\left(-\beta \delta k_{2} v_{1}+\beta k_{2} v_{1}^{2}-\eta \gamma\right)}{n_{2}} \\
1
\end{array}\right],
$$$$
x_{3}=\left[\begin{array}{c}
\frac{\beta\left(\beta \delta \eta k_{1} k_{2}-\beta \eta k_{1} k_{2} v_{2}+2 \delta \eta k_{1}-2 \eta k_{1} v_{2}-k_{2} \gamma v_{2}\right)}{n_{3}} \\
\frac{\beta^{2} \delta^{2} k_{1} k_{2}-\operatorname{beta}^{2} k_{1} k_{2} v_{2}^{2}+2 \beta \delta^{2} k_{1}-2 \beta k_{1} v_{2}^{2}-\gamma^{2}}{n_{3}} \\
\frac{k_{1} \gamma\left(-\beta \delta k_{2} v_{2}-\beta k_{2} v_{2}^{2}+\eta \gamma\right)}{n_{3}} \\
1
\end{array}\right],
$$$$
x_{4}=\left[\begin{array}{c}
-\frac{\beta\left(\beta \delta \eta k_{1} k_{2}+\beta \eta k_{1} k_{2} v_{2}+2 \delta \eta k_{1}+2 \eta k_{1} v_{2}+k_{2} \gamma v_{2}\right)}{n_{4}} \\
-\frac{\beta^{2} \delta^{2} k_{2} k_{2}-\text { beta }^{2} k_{1} k_{2} v_{2}^{2}+2 \beta \delta^{2} k_{1}-2 \beta k_{1} v_{2}^{2}-\gamma^{2}}{n_{4}} \\
\frac{k_{1} \gamma\left(-\beta \delta k_{2} v_{2}+\beta k_{2} v_{2}^{2}-\eta \gamma\right)}{n_{4}} \\
1
\end{array}\right],
$$$$
n_{1}=k_{2}\left(2 \beta \delta^{2} k_{1} v_{1}+\beta \delta \eta k_{1} \gamma-\beta \eta k_{1} \gamma v_{1}-2 \beta k_{1} v_{1}^{3}-\gamma^{2} v_{1}\right) \text {, }
$$$$
n_{2}=k_{2}\left(2 \beta \delta^{2} k_{1} v_{1}-\beta \delta \eta k_{1} \gamma-\beta \eta k_{1} \gamma v_{1}-2 \beta k_{1} v_{1}^{3}-\gamma^{2} v_{1}\right) \text {, }
$$$$
n_{3}=k_{2}\left(2 \beta \delta^{2} k_{1} v_{2}+\beta \delta \eta k_{1} \gamma-\beta \eta k_{1} \gamma v_{2}-2 \beta k_{1} v_{2}^{3}-\gamma^{2} v_{2}\right) \text {, }
$$$$
n_{4}=k_{2}\left(2 \beta \delta^{2} k_{1} v_{2}-\beta \delta \eta k_{1} \gamma-\beta \eta k_{1} \gamma v_{2}-2 \beta k_{1} v_{2}^{3}-\gamma^{2} v_{2}\right) \text {. }
$$ 
Therefore, we have

$$
\left[\begin{array}{c}
G \\
I \\
\lambda_{1} \\
\lambda_{2}
\end{array}\right]=H\left[\begin{array}{cccc}
e^{r_{1} t} & 0 & 0 & 0 \\
0 & e^{r_{2} t} & 0 & 0 \\
0 & 0 & e^{r_{3} t} & 0 \\
0 & 0 & 0 & e^{r_{4} t}
\end{array}\right]\left[\begin{array}{c}
c_{1} \\
c_{2} \\
c_{3} \\
c_{4}
\end{array}\right]-A^{-1} B .
$$

Hence, the optimal goodwill and inventory can be given in Proposition 1. Combining the functions (13)-(15), we can obtain the optimal pricing, advertising, and production strategies. With the four boundary conditions $G(0)=G_{0}$, $I(0)=I_{0}, \quad I(T)=0$, and $\lambda_{1}(T)=0$, we can obtain $c_{1}, c_{2}, c_{3}, c_{4}$ as

$$
\begin{aligned}
& c_{1}=\left(\left(a_{12} a_{23}-a_{13} a_{22}\right)\left(a_{34} b_{4}-a_{44} b_{3}\right)+\left(a_{13} a_{24}-a_{14} a_{23}\right)\left(a_{32} b_{4}-a_{42} b_{3}\right)\right. \\
& +\left(a_{14} a_{22}-a_{12} a_{24}\right)\left(a_{33} b_{4}-a_{43} b_{3}\right)+\left(a_{33} a_{44}-a_{34} a_{43}\right)\left(a_{12} b_{2}-a_{22} b_{1}\right) \\
& \left.+\left(a_{32} a_{44}-a_{34} a_{42}\right)\left(a_{23} b_{2}-a_{13} b_{1}\right)+\left(a_{32} a_{43}-a_{33} a_{42}\right)\left(a_{14} b_{2}-a_{24} b_{1}\right)\right) \\
& \text { - }\left(\left(a_{11} a_{22}-a_{12} a_{21}\right)\left(a_{33} a_{44}-a_{34} a_{43}\right)+\left(a_{12} a_{31}-a_{11} a_{32}\right)\left(a_{23} a_{44}-a_{24} a_{43}\right)\right. \\
& +\left(a_{11} a_{42}-a_{12} a_{41}\right)\left(a_{23} a_{34}-a_{24} a_{33}\right)+\left(a_{13} a_{44}-a_{14} a_{43}\right)\left(a_{21} a_{32}-a_{22} a_{31}\right) \\
& \left.+\left(a_{14} a_{33}-a_{13} a_{34}\right)\left(a_{21} a_{42}-a_{22} a_{41}\right)+\left(a_{13} a_{24}-a_{14} a_{23}\right)\left(a_{31} a_{42}-a_{32} a_{41}\right)\right)^{-1} \text {, } \\
& c_{2}=-\left(\left(a_{11} a_{23}-a_{13} a_{21}\right)\left(a_{34} b_{4}-a_{44} b_{3}\right)+\left(a_{11} a_{24}-a_{14} a_{21}\right)\left(a_{43} b_{3}-a_{33} b_{4}\right)\right. \\
& +\left(a_{13} a_{24}-a_{14} a_{23}\right)\left(a_{31} b_{4}-a_{41} b_{3}\right)+\left(a_{33} a_{44}-a_{34} a_{43}\right)\left(a_{11} b_{2}-a_{21} b_{1}\right) \\
& \left.+\left(a_{31} a_{44}-a_{34} a_{41}\right)\left(a_{23} b_{1}-a_{13} b_{2}\right)+\left(a_{31} a_{43}-a_{33} a_{41}\right)\left(a_{14} b_{2}-a_{24} b_{1}\right)\right) \\
& \text { - }\left(\left(a_{11} a_{22}-a_{12} a_{21}\right)\left(a_{33} a_{44}-a_{34} a_{43}\right)+\left(a_{12} a_{31}-a_{11} a_{32}\right)\left(a_{23} a_{44}-a_{24} a_{43}\right)\right. \\
& +\left(a_{11} a_{42}-a_{12} a_{41}\right)\left(a_{23} a_{34}-a_{24} a_{33}\right)+\left(a_{13} a_{44}-a_{14} a_{43}\right)\left(a_{21} a_{32}-a_{22} a_{31}\right) \\
& \left.+\left(a_{14} a_{33}-a_{13} a_{34}\right)\left(a_{21} a_{42}-a_{22} a_{41}\right)+\left(a_{13} a_{24}-a_{14} a_{23}\right)\left(a_{31} a_{42}-a_{32} a_{41}\right)\right)^{-1} \text {, } \\
& c_{3}=\left(\left(a_{11} a_{22}-a_{12} a_{21}\right)\left(a_{34} b_{4}-a_{44} b_{3}\right)+\left(a_{11} a_{24}-a_{14} a_{21}\right)\left(a_{42} b_{3}-a_{32} b_{4}\right)\right. \\
& +\left(a_{12} a_{24}-a_{14} a_{22}\right)\left(a_{31} b_{4}-a_{41} b_{3}\right)+\left(a_{32} a_{44}-a_{34} a_{42}\right)\left(a_{11} b_{2}-a_{21} b_{1}\right) \\
& \left.+\left(a_{31} a_{44}-a_{34} a_{41}\right)\left(a_{22} b_{1}-a_{12} b_{2}\right)+\left(a_{31} a_{42}-a_{32} a_{41}\right)\left(a_{14} b_{2}-a_{24} b_{1}\right)\right) \\
& \text { - }\left(\left(a_{11} a_{22}-a_{12} a_{21}\right)\left(a_{33} a_{44}-a_{34} a_{43}\right)+\left(a_{12} a_{31}-a_{11} a_{32}\right)\left(a_{23} a_{44}-a_{24} a_{43}\right)\right. \\
& +\left(a_{11} a_{42}-a_{12} a_{41}\right)\left(a_{23} a_{34}-a_{24} a_{33}\right)+\left(a_{13} a_{44}-a_{14} a_{43}\right)\left(a_{21} a_{32}-a_{22} a_{31}\right) \\
& \left.+\left(a_{14} a_{33}-a_{13} a_{34}\right)\left(a_{21} a_{42}-a_{22} a_{41}\right)+\left(a_{13} a_{24}-a_{14} a_{23}\right)\left(a_{31} a_{42}-a_{32} a_{41}\right)\right)^{-1} \text {, } \\
& c_{4}=-\left(\left(a_{11} a_{22}-a_{12} a_{21}\right)\left(a_{33} b_{4}-a_{43} b_{3}\right)+\left(a_{11} a_{23}-a_{13} a_{21}\right)\left(a_{42} b_{4}-a_{42} b_{3}\right)\right. \\
& +\left(a_{12} a_{23}-a_{13} a_{22}\right)\left(a_{31} b_{4}-a_{41} b_{3}\right)+\left(a_{32} a_{43}-a_{33} a_{42}\right)\left(a_{11} b_{2}-a_{21} b_{1}\right) \\
& \left.+\left(a_{31} a_{43}-a_{33} a_{41}\right)\left(a_{22} b_{1}-a_{12} b_{2}\right)+\left(a_{31} a_{42}-a_{32} a_{41}\right)\left(a_{13} b_{2}-a_{23} b_{1}\right)\right) \\
& \cdot\left(\left(a_{11} a_{22}-a_{12} a_{21}\right)\left(a_{33} a_{44}-a_{34} a_{43}\right)+\left(a_{11} a_{32}-a_{12} a_{31}\right)\left(a_{23} a_{44}-a_{24} a_{43}\right)\right. \\
& +\left(a_{11} a_{42}-a_{12} a_{41}\right)\left(a_{23} a_{34}-a_{24} a_{33}\right)+\left(a_{13} a_{44}-a_{14} a_{43}\right)\left(a_{21} a_{32}-a_{22} a_{31}\right) \\
& \left.+\left(a_{14} a_{33}-a_{13} a_{34}\right)\left(a_{21} a_{42}-a_{22} a_{41}\right)+\left(a_{13} a_{24}-a_{14} a_{23}\right)\left(a_{31} a_{42}-a_{32} a_{41}\right)\right)^{-1},
\end{aligned}
$$


where

$$
\begin{aligned}
& w=2 \beta^{2} \delta^{2} h k_{1} k_{2}+4 \beta \delta^{2} h k_{1}-\eta^{2} k_{1} \gamma^{2}-2 h \gamma^{2}, \\
& a_{11}=\frac{\beta\left(\beta \delta \eta k_{1} k_{2}-\beta \eta k_{1} k_{2} v_{1}+2 \delta \eta k_{1}-2 \eta k_{1} v_{1}-k_{2} \gamma v_{1}\right)}{n_{1}} \text {, } \\
& a_{12}=-\frac{\beta\left(\beta \delta \eta k_{1} k_{2}+\beta \eta k_{1} k_{2} v_{1}+2 \delta \eta k_{1}+2 \eta k_{1} v_{1}+k_{2} \gamma v_{1}\right)}{n_{2}}, \\
& a_{13}=\frac{\beta\left(\beta \delta \eta k_{1} k_{2}-\beta \eta k_{1} k_{2} v_{2}+2 \delta \eta k_{1}-2 \eta k_{1} v_{2}-k_{2} \gamma v_{2}\right)}{n_{3}}, \\
& a_{14}=-\frac{\beta\left(\beta \delta \eta k_{1} k_{2}+\beta \eta k_{1} k_{2} v_{2}+2 \delta \eta k_{1}+2 \eta k_{1} v_{2}+k_{2} \gamma v_{2}\right)}{n_{4}}, \\
& a_{21}=\frac{\beta^{2} \delta^{2} k_{1} k_{2}-\beta^{2} k_{1} k_{2} v_{1}^{2}+2 \beta \delta^{2} k_{1}-2 \beta k_{1} v_{1}^{2}-\gamma^{2}}{n_{1}}, \\
& a_{22}=-\frac{\beta^{2} \delta^{2} k_{1} k_{2}-\beta^{2} k_{1} k_{2} v_{1}^{2}+2 \beta \delta^{2} k_{1}-2 \beta k_{1} v_{1}^{2}-\gamma^{2}}{n_{2}}, \\
& a_{23}=\frac{\beta^{2} \delta^{2} k_{1} k_{2}-\beta^{2} k_{1} k_{2} v_{2}^{2}+2 \beta \delta^{2} k_{1}-2 \beta k_{1} v_{2}^{2}-\gamma^{2}}{n_{3}}, \\
& a_{24}=-\frac{\beta^{2} \delta^{2} k_{1} k_{2}-\beta^{2} k_{1} k_{2} v_{2}^{2}+2 \beta \delta^{2} k_{1}-2 \beta k_{1} v_{2}^{2}-\gamma^{2}}{n_{4}}, \\
& a_{31}=\frac{k_{1} \gamma\left(-\beta \delta k_{2} v_{1}-\beta k_{2} v_{1}^{2}+\eta \gamma\right)}{n_{1}} e^{v_{1} T}, \\
& a_{32}=\frac{k_{1} \gamma\left(-\beta \delta k_{2} v_{1}+\beta k_{2} v_{1}^{2}-\eta \gamma\right)}{n_{2}} e^{-v_{1} T}, \\
& a_{33}=\frac{k_{1} \gamma\left(-\beta \delta k_{2} v_{2}-\beta k_{2} v_{2}^{2}+\eta \gamma\right)}{n_{3}} e^{v_{2} T} \text {, } \\
& a_{34}=\frac{k_{1} \gamma\left(-\beta \delta k_{2} v_{2}+\beta k_{2} v_{2}^{2}-\eta \gamma\right)}{n_{4}} e^{-v_{2} T} \text {, } \\
& a_{41}=\frac{\beta^{2} \delta^{2} k_{1} k_{2}-\beta^{2} k_{1} k_{2} v_{1}^{2}+2 \beta \delta^{2} k_{1}-2 \beta k_{1} v_{1}^{2}-\gamma^{2}}{n_{1}} e^{v_{1} T}, \\
& a_{42}=-\frac{\beta^{2} \delta^{2} k_{1} k_{2}-\beta^{2} k_{1} k_{2} v_{1}^{2}+2 \beta \delta^{2} k_{1}-2 \beta k_{1} v_{1}^{2}-\gamma^{2}}{n_{2}} e^{-v_{1} T}, \\
& a_{43}=\frac{\beta^{2} \delta^{2} k_{1} k_{2}-\beta^{2} k_{1} k_{2} v_{2}^{2}+2 \beta \delta^{2} k_{1}-2 \beta k_{1} v_{2}^{2}-\gamma^{2}}{n_{3}} e^{v_{2} T}, \\
& a_{44}=-\frac{\beta^{2} \delta^{2} k_{1} k_{2}-\beta^{2} k_{1} k_{2} v_{2}^{2}+2 \beta \delta^{2} k_{1}-2 \beta k_{1} v_{2}^{2}-\gamma^{2}}{n_{4}} e^{-v_{2} T} \text {, } \\
& b_{1}=\frac{\left(\beta k_{2}+2\right)\left(\eta^{2} k_{1}+2 h\right) \alpha \gamma-\left(\eta^{2} k_{1}+2 h\right) \alpha \gamma \beta k_{2}}{2 w}-G_{0} \text {, } \\
& b_{2}=\frac{\left(\beta k_{2}+2\right) \eta \delta \alpha \gamma k_{1}-\alpha \eta \delta \gamma \beta k_{1} k_{2}}{2 w}-I_{0} \\
& b_{3}=\frac{\left(\beta k_{2}+2\right) h \delta \alpha \gamma k_{1}-\alpha \gamma \beta \delta h k_{1} k_{2}}{2 w} \\
& b_{4}=\frac{\left(\beta k_{2}+2\right) \eta \delta \alpha \gamma k_{1}-\alpha \eta \delta \gamma \beta k_{1} k_{2}}{2 w}
\end{aligned}
$$

\section{Data Availability}

The data used to support the findings of this study are included within the paper.

\section{Conflicts of Interest}

The authors declare that no conflicts of interest exist with regard to the publication of this paper.

\section{Acknowledgments}

The work was supported by the National Natural Science Foundation of China (Grant no. 71971152), the Key Scientific Research Projects of Colleges and Universities of Henan Province (no. 20B630002), the Foundation for Excellent Youth Teachers of Colleges and Universities of Henan Province under Grant no. 2019GGJS195, and 2018 Research and Development Fund of Anyang Normal University (no. AYNUKP-2018-B25).

\section{References}

[1] A. K. Pal, A. K. Bhunia, R. N. Mukherjee et al., "A marketingoriented inventory model with three-component demand rate dependent on displayed stock level (DSL)," Journal of the Operational Research Society, vol. 56, no. 1, pp. 113-118, 2005.

[2] R. I. Levin, C. P. McLaughlin, R. P. Lamone, and J. F. Kottas, Production/Operations Management Contemporary Policy for Managing Operating Systems, McGraw-Hill, New York, NY, USA, 1972.

[3] C.-T. Yang, L.-Y. Ouyang, K.-S. Wu, and H.-F. Yen, "An optimal replenishment policy for deteriorating items with stock-dependent demand and relaxed terminal conditions under limited storage space," Central European Journal of Operations Research, vol. 19, no. 1, pp. 139-153, 2011.

[4] R. Gupta and P. Vrat, "Inventory model for stock-dependent consumption rate," Opsearch, vol. 23, no. 1, pp. 19-24, 1986.

[5] T. L. Urban, "Inventory models with inventory-level-dependent demand: a comprehensive review and unifying theory," European Journal of Operational Research, vol. 162, no. 3, pp. 792-804, 2005.

[6] A. Khanna, P. Gautam, B. Sarkar, and C. K. Jaggi, "Integrated vendor-buyer strategies for imperfect production systems with maintenance and warranty policy," RAIRO-Operations Research, vol. 54, no. 2, pp. 435-450, 2020.

[7] B. Khara, J. K. Dey, S. K. Mondal et al., "Sustainable recycling in an imperfect production system with acceptance quality level dependent development cost and demand," Computers \& Industrial Engineering, vol. 142, p. 106300, 2020.

[8] H. K. Alfares, "Inventory model with stock-level dependent demand rate and variable holding cost," International Journal of Production Economics, vol. 108, no. 1-2, pp. 259-265, 2007.

[9] Y. C. Wei and H. W. Wang, "The impact of stock-dependent demand on supply chain dynamics," Applied Mathematical Modelling, vol. 37, no. 18-19, pp. 8348-8362, 2013.

[10] L. Lu, J. Zhang, and W. Tang, "Optimal dynamic pricing and replenishment policy for perishable items with inventorylevel-dependent demand," International Journal of Systems Science, vol. 47, no. 6, pp. 1480-1494, 2016.

[11] J. X. Zhang, Y. Wang, L. H. Lu, and W. S. Tang, "Optimal dynamic pricing and replenishment cycle for non-instantaneous deterioration items with inventory-level-dependent 
demand," International Journal of Production Economics, vol. 170, no. A, pp. 136-145, 2016.

[12] S. Bhaskaran, K. Ramachandran, and J. Semple, "A dynamic inventory model with the right of refusal," Management Science, vol. 56, no. 12, pp. 2265-2281, 2010.

[13] S. M. R. Iravani, T. Liu, and D. Simchi-Levi, "Optimal production and admission policies in make-to-stock/make-toorder manufacturing systems," Production and Operations Management, vol. 21, no. 2, pp. 224-235, 2012.

[14] K. J. Chandra, G. Prerna, and K. Aditi, "Credit policies for deteriorating imperfect quality items with exponentially increasing demand and partial backlogging," in Handbook of Research on Promoting Business Process Improvement through Inventory Control Techniques, pp. 90-106, IGI Global, Hershey, PA, USA, 2018.

[15] K. R. Ramkishore and R. K. Amit, "Optimal bargaining mechanisms with refusal cost," International Journal of Operational Research, vol. 35, no. 1, pp. 54-66, 2019.

[16] K. J. Chandra, G. Prerna, and K. Aditi, "Inventory decisions for imperfect quality deteriorating items with exponential declining demand under trade credit and partially backlogged shortages," Quality, IT and Business Operations, pp. 213-229, Springer, Singapore, 2018.

[17] M. V. Marn, E. V. Roegner, and C. C. Zawada, "The power of pricing," McKinsey Quarterly, vol. 1, pp. 26-39, 2003.

[18] P. Nelson, "Information and consumer behavior," Journal of Political Economy, vol. 78, no. 2, pp. 311-329, 1970.

[19] A. Guttmann, Global Advertising Spending from 2010 to 2019, https://www.statista.com/statistics/236943/global-advertisingspending, 2019.

[20] R. Dorfman and P. O. Steiner, "Optimal advertising and optimal quality," The American Economic Review, vol. 44, no. 5, pp. 826-836, 1954.

[21] V. Mahajan, E. Muller, and F. M. Bass, "New product diffusion models in marketing: a review and directions for research," Journal of Marketing, vol. 54, no. 1, pp. 1-26, 1990.

[22] K. Bagwell, "Chapter 28 the economic analysis of advertising," Handbook of Industrial Organization, vol. 3, pp. 1701-1844, 2007.

[23] Y. B. Chen and J. H. Xie, "Third-party product review and firm marketing strategy," Marketing Science, vol. 24, no. 2, pp. 218-240, 2016.

[24] A. A. Taleizadeh, M. K. Mamaghan, and S. A. Torabi, "A possibilistic closed-loop supply chain: pricing, advertising and remanufacturing optimization," Neural Computing and Applications, vol. 32, no. 4, pp. 1195-1215, 2018.

[25] M. R. Baye and J. Morgan, "Brand and price advertising in online markets," Management Science, vol. 55, no. 7, pp. 1139-1151, 2009.

[26] M. M. SeyedEsfahani, M. Biazaran, and M. Gharakhani, "A game theoretic approach to coordinate pricing and vertical co-op advertising in manufacturer-retailer supply chains," European Journal of Operational Research, vol. 211, no. 2, pp. 263-273, 2011.

[27] J. Yue, J. Austin, Z. Huang, and B. Chen, "Pricing and advertisement in a manufacturer-retailer supply chain," European Journal of Operational Research, vol. 231, no. 2, pp. 492-502, 2013.

[28] S. Karray and G. Martín-Herrán, "Fighting store brands through the strategic timing of pricing and advertising decisions," European Journal of Operational Research, vol. 275, no. 2, pp. 635-647, 2019.

[29] S. P. Sethi, A. Prasad, and X. He, "Optimal advertising and pricing in a new-product adoption model," Journal of
Optimization Theory and Applications, vol. 139, no. 2, pp. 351-360, 2008.

[30] K. Helmes, R. Schlosser, and M. Weber, "Optimal advertising and pricing in a class of general new-product adoption models," European Journal of Operational Research, vol. 229, no. 2, pp. 433-443, 2013.

[31] X. He, A. Prasad, and S. P. Sethi, "Cooperative advertising and pricing in a dynamic stochastic supply chain: feedback stackelberg strategies," Production and Operations Management, vol. 18, no. 1, pp. 78-94, 2009.

[32] A. Chutani and S. P. Sethi, "Optimal advertising and pricing in a dynamic durable goods supply chain," Journal of Optimization Theory and Applications, vol. 154, no. 2, pp. 615-643, 2012.

[33] G. Liu, J. Zhang, and W. Tang, "Strategic transfer pricing in a marketing-operations interface with quality level and advertising dependent goodwill," Omega, vol. 56, pp. 1-15, 2015.

[34] L. Feng, J. X. Zhang, and W. S. Tang, "A joint dynamic pricing and advertising model of perishable products," Journal of the Operational Research Society, vol. 66, no. 8, pp. 1341-1351, 2014.

[35] Z. Wu, L. Feng, and D. Chen, "Coordinating pricing and advertising decisions for supply chain under consignment contract in the dynamic setting," Complexity, vol. 2018, Article ID 7697180, 11 pages, 2018.

[36] F. El Ouardighi, S. Jørgensen, and F. Pasin, "A dynamic game of operations and marketing management in a supply chain," International Game Theory Review, vol. 10, no. 4, pp. 373-397, 2008.

[37] P. De Giovanni, "An optimal control model with defective products and goodwill damages," Annals of Operations Research, vol. 289, no. 2, pp. 419-430, 2019.

[38] M. Nerlove and K. J. Arrow, "Optimal advertising policy under dynamic conditions," Economica, vol. 29, no. 114, pp. 129-142, 1962.

[39] P. De Giovanni, "Quality improvement vs. advertising support: which strategy works better for a manufacture?" European Journal of Operational Research, vol. 208, no. 2, pp. 199-130, 2011.

[40] G. M. Erickson, "Transfer pricing in a dynamic marketingoperations interface," European Journal of Operational Research, vol. 216, no. 2, pp. 326-333, 2012.

[41] T. Li, D. Yan, and X. Ma, "Stability analysis and chaos control of recycling price game model for manufacturers and retailers," Complexity, vol. 2019, Article ID 3157407, 13 pages, 2019.

[42] C. M. Erickson, "A differential game model of the marketingoperations interface," European Journal of Operational Research, vol. 211, no. 2, pp. 394-402, 2010.

[43] D. Pekelman, "Simultaneous price-production decisions," Operations Research, vol. 22, no. 4, pp. 788-794, 1974.

[44] A. Prasad and S. P. Sethi, "Competitive advertising under uncertainty: a stochastic differential game approach," Journal of Optimization Theory and Applications, vol. 123, no. 1, pp. 163-185, 2004.

[45] G. Zaccour, "On the coordination of dynamic marketing channels and two-part tariffs," Automatica, vol. 44, no. 5, pp. 1233-1239, 2008.

[46] Y. Wang and X. Sun, "Dynamic vs. static wholesale pricing strategies in a dual-channel green supply chain," Complexity, vol. 2019, Article ID 8497070, 14 pages, 2019.

[47] G. Feichtinger and R. Hartl, "Optimal pricing and production in an inventory model," European Journal of Operational Research, vol. 19, no. 1, pp. 45-56, 1985. 
[48] S. P. Sethi and G. L. Thompson, Optimal Control Theory: Applications to Management Science and Economics, Kluwer, Dordrecht, Netherlands, 2000.

[49] P. Gautam and A. Khanna, "An imperfect production inventory model with setup cost reduction and carbon emission for an integrated supply chain," Uncertain Supply Chain Management, vol. 6, no. 3, pp. 271-286, 2018.

[50] P. Gautam, A. Kishore, A. Khanna, and C. K. Jaggi, "Strategic defect management for a sustainable green supply chain," Journal of Cleaner Production, vol. 233, pp. 226-241, 2019.

[51] A. Kishore, P. Gautam, A. Khanna et al., "Investigating the effect of learning in set-up cost for imperfect production systems by utilizing two-way inspection plan for rework under screening constraints," Scientia Iranica, 2019, in press. 